
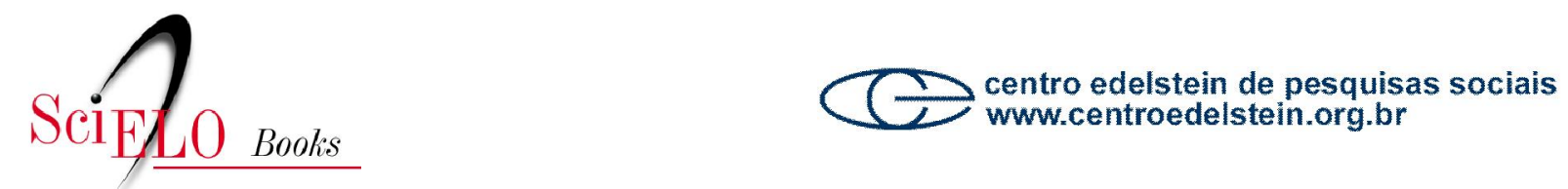

\title{
Programa nacional de produção e uso do biodiesel
}

\author{
Jozimar de Paes Almeida
}

SciELO Books / SciELO Livros / SciELO Libros

ALMEIDA, JP. Biodiesel o "Óleo Filosofal”: desafios para a educação ambiental no caldeirão do "desenvolvimento sustentável” [online]. Rio de Janeiro: Centro Edelstein de Pesquisas Sociais, 2010. pp. 18-45. Programa nacional de produção e uso do biodiesel. ISBN: 978-85-7982-027-4. Available from SciELO Books $<\underline{\text { http://books.scielo.org }>\text {. }}$

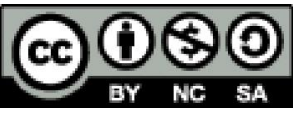

All the contents of this chapter, except where otherwise noted, is licensed under a Creative Commons Attribution-Non Commercial-ShareAlike 3.0 Unported.

Todo o conteúdo deste capítulo, exceto quando houver ressalva, é publicado sob a licença Creative Commons Atribuição Uso Não Comercial - Partilha nos Mesmos Termos 3.0 Não adaptada.

Todo el contenido de este capítulo, excepto donde se indique lo contrario, está bajo licencia de la licencia Creative Commons Reconocimento-NoComercial-CompartirIgual 3.0 Unported. 


\section{Programa Nacional de Produção e Uso do Biodiesel.}

O fogo do biodiesel, embriagando corações e mentes

O governo brasileiro, presidido por Luiz Inácio Lula da Silva, instituiu por decreto em 02 de julho de 2003, um Grupo de Trabalho Interministerial encarregado de apresentar estudos sobre a viabilidade de utilização de biodiesel como fonte alternativa de energia. Como resultado foi elaborado um relatório que deu embasamento ao Presidente da República para estabelecer o PNPB como ação estratégica e prioritária para o Brasil. Por meio deste Programa, o Governo Federal organizou a cadeia produtiva, definiu as linhas de financiamento, estruturou a base tecnológica e editou o marco regulatório do novo combustível.

Esta intervenção governamental direta na economia de mercado, não é estranha perante aos moldes capitalistas, que ora expressam que a economia deve se autoregular pelo mercado, excluindo o estado como elemento regulador, para aferirem maiores lucros e, em outros momentos, quando são necessários investimentos de risco e a fundo perdido, suplicam o amparo estatal, para garantir preço mínimo, mercado consumidor, condições subsidiadas de produção, fazendo assim, com que os cofres públicos aventurem-se nas custas e riscos do empreendimento e os lucros possam ser privatizados. Mas será que este procedimento se repete neste Programa? Vejamos quais são os seus objetivos e diretrizes:

[...] programa interministerial do Governo Federal que objetiva a implementação de forma sustentável, tanto técnica, como economicamente, produção e uso do Biodiesel, com enfoque na inclusão social e no desenvolvimento regional, via geração de emprego e renda. Principais diretrizes do PNPB: - Implantar um programa sustentável, promovendo inclusão social; • Garantir preços competitivos, qualidade e suprimento; • Produzir o biodiesel a partir de diferentes fontes oleaginosas e em regiões diversas. A Lei $\mathrm{n}^{\circ}$ 11.097, de 13 de janeiro de 2005, estabelece a obrigatoriedade da adição de um percentual mínimo de biodiesel ao óleo diese comercializado ao consumidor, em qualquer parte do território nacional. Esse percentual obrigatório será de 5\% oito anos após a publicação da referida lei, havendo um percentual obrigatório intermediário de $2 \%$ três anos após a publicação da mesma ${ }^{18}$.

Lê-mos no texto e com os destaques dos grifos, a preocupação com a realização de um desenvolvimento sustentável, de forma técnica e econômica, enfocando a inclusão social pela geração de emprego e renda atendendo as regiões brasileiras. Destaque-se inicialmente, que os percentuais obrigatórios de inclusão do biodiesel ao petrodiesel já estão sendo antecipados por reivindicação dos produtores de soja:

Em reunião na última quinta no Palácio do Planalto, ficou praticamente acertado que o percentual de 5\% de mistura será obrigatório a partir de 2010, e não de 2013, como inicialmente previsto. A antecipação atende, em parte, ao pedido dos produtores, porque aumenta a demanda pelo produto, dando mais segurança aos investimentos que estão sendo feitos. Para dar garantia ao negócio, no entanto, os investidores (em sua maioria de soja) querem mais: que a mistura obrigatória de $2 \%$ também seja antecipada, de janeiro de 2008 para julho de $2007[\ldots]^{19}$.

Quanto às diretrizes do Programa, além da sustentabilidade e inclusões sociais já referidas nos objetivos, considera-se a necessidade de garantia de preços competitivos, qualidade e suprimento do produto 'biodiesel', que deveria ser extraído de diferentes fontes oleaginosas em diversas regiões. Destaca-se também, a garantia expressa em lei de se criar obrigatoriamente um mercado consumidor. Nossa preocupação foi analisar se até agora estes objetivos e diretrizes estão sendo cumpridos e de que forma isto estaria ocorrendo. Vamos nos posicionar mais precisamente sobre esta questão no decorrer deste trabalho.

A utilização de óleos vegetais para geração de energia no Brasil, teve seu estudo governamental iniciado em 1975, pelo Ministério da Agricultura através do Proóleo, Plano de Produção de Óleos Vegetais para fins Energéticos. Previa-se inicialmente uma mistura de $30 \%$ de óleo vegetal com previsão de substituição integral do petrodiesel.

\footnotetext{
18 Ministério da Ciência e Tecnologia, Programa do Biodiesel: Objetivos e Diretrizes. http://www.biodiesel.gov.br/ acesso em 25/04/2007 (grifo nosso).

${ }^{19}$ CRUZ, Valdo e MEDINA, Humberto. Lula deve antecipar mistura de biodiesel. Folha de $S P, 26 / 12 / 06$. (JC e-mail 3170) http://www.jornaldaciencia.org.br acesso em 26/12/2006.
} 
Entendia-se assim, que haveria uma mudança estrutural na economia e seu sistema de produção e consumo, afetando diretamente o campo, a indústria, o ambiente e o sistema de geração de emprego e renda ${ }^{20}$. Este Plano não foi implantado e não possuímos mais dados dos motivos de sua não implantação. Quem sabe, e ponderações históricas se realizam também por cogitação, o direcionamento dos esforços governamentais, para a substituição de petróleo empregou seu maiores esforços no Plano do Próálcool e sobre ele realizamos uma análise pormenorizada ${ }^{21}$.

A utilização de óleo vegetal como combustível para acionar motores não era inédita em 1975, pois em 1900 na exposição mundial de Paris um motor diesel consumindo óleo de amendoim deu mostras de sua eficácia e apresentou publicamente o biodiesel. Este óleo combustível, oriundo da biomassa pode ser assim definido: Combustível produzido a partir de óleos vegetais, novos ou usados, ou gorduras animais, por intermédio de um processo químico industrial em que se utiliza álcool (metílico ou etílico), catalisador (soda cáustica ou hidróxido de potássio), resultando no biocombustível, glicerina, éster, resíduos do esmagamento da biomassa e água $^{22}$.

O aproveitamento do biocombustível ocorre na queima em geradores ou motores. Na indústria, a glicerina pode ser utilizada como matéria prima para fabricação de cosméticos, tintas, têxteis. Os resíduos sólidos do esmagamento das sementes podem tornar-se ração animal e adubos orgânicos. Quanto à água ela pode ser reutilizada, desde que, sofra um processo de purificação.

Com o intuito de consolidar o PNPB o poder federal estabelece uma série de medidas legais e de amparo fiscal, econômico e científico. Leis, resoluções e instruções normativas expressam este apoio. Instituições governamentais em níveis federal e estadual, com seus: ministérios, secretarias de estado, bancos públicos (Banco do Brasil, BNDES, etc), instituições de pesquisa (FINEP, Embrapa, FAPESP, FAPERJ, Fundação

${ }^{20}$ Conselho Nacional de Desenvolvimento Rural Sustentável. Dossiê Biodiesel,

${ }^{21}$ PAES DE ALMEIDA, Jozimar. A extinção do Arco-íris: Ecologia e História, Campinas: Papirus, 1988

${ }^{22}$ COPPE. Projeto Biodiesel, http://www.ivig.coppe.ufrj.br/pbr/ proj_biodiesel.htm acesso em $02 / 01 / 2006$.
Araucária, etc.), e universidades com equipes de pesquisa (Esalq, COPPE, etc).

Um gigantesco aparato estatal é mobilizado para a consecução do Programa. Dentre este aparato vejamos para quais atividades são direcionadas o apoio do BNDES e como ele ocorre.

Apoiar investimentos em todas as fases da produção de biodiesel (fase agrícola, produção de óleo bruto, produção de biodiesel, armazenamento, logística e equipamentos para a produção de biodiesel), a aquisição de máquinas e equipamentos homologados para uso de biodiesel ou de óleo vegetal bruto; investimentos em beneficiamento de co-produtos e subprodutos do biodiesel ${ }^{23}$.

Este apoio de investimentos vincula-se a uma preocupação de estabelecer condições mais propícias à quem possuir o selo Combustível Social, pois o Programa propõe a inclusão social dos agricultores familiares, gerando emprego e renda, desta forma estaria respondendo aos objetivos propostos. Este selo, concedido aos produtores de biodiesel é administrado pelo Ministério do Desenvolvimento Agrário e concede ao seu possuidor condições de reduções de impostos, de juros em empréstimos bancários, possibilitando inclusive uma promoção comercial da empresa e, para que o selo seja concedido é necessário que cumpram as seguintes exigências: mínimo de:

- Comprem matéria-prima da agricultura familiar em percentual

- 50\% região Nordeste e Semi-árido;

- $10 \%$ região Norte e Centro Oeste e,

- 30\% região Sudeste e Sul.

- Façam contratos negociados com os agricultores familiares, constando, pelo menos: O prazo contratual; $\mathrm{O}$ valor de compra e critérios de reajuste do preço contratado; As condições de entrega da matéria-prima; As salvaguardas de cada parte e, Identificação e concordância de uma representação dos agricultores que participou das negociações.

23 Banco Nacional de Desenvolvimento Econômico e Social. (BNDES), Programas, Biodiesel. http://www.bndes.gov.br/programas/infra/biodiesel.asp acesso em 03/03/2006. 
- Assegurem assistência e capacitação técnicaaos agricultores familiares $^{24}$.

Pode-se notar a preocupação com defesa da agricultura familiar, no entanto, não se explicita o porquê destas diferentes porcentagens entre as diversas regiões ou, se efetuada a compra na percentagem mínima de uma região poderia se excluir a obrigatoriedade da compra em outras regiões.

Quanto à participação do BNDES no financiamento dos projetos com este selo, ele financia até $90 \%$ (noventa por cento) dos itens passíveis de apoio e cobra das micros, pequenas e médias empresas a Taxa de Juro de Longo Prazo (TJLP) + $1 \%$ ao ano, no caso das grandes empresas a TJLP + $2 \%$ ao ano.

Percebe-se assim, devido ao elevado índice de financiamento e da reduzida cobrança da taxa de juros, uma priorização ao Selo Combustível Social, no entanto, se aproximarmos estes dados e os compararmos com o mesmo apoio dado pela instituição financeira aos produtores que não tem o referido Selo, veremos que os índices não são assim tão díspares, por exemplo, o BNDES apóia em $80 \%$ os mesmos itens financiados e cobra uma taxa de juros de $1 \%$ (um por cento) a mais, do que está sendo cobrada para as micros, pequenas, médias e grandes empresas ${ }^{25}$.

Será que ao ponderar sobre estes índices, que não são tão díspares, poderíamos colocar em dúvida a prioridade proposta no objetivo do PNPB? Estamos entendendo que esta alegada prioridade à agricultura familiar não é consistente, vamos continuar nossa explanação.

Além da obrigatoriedade de adição de biodiesel ao petrodiesel e do apoio em financiamento, temos também a renúncia fiscal expressa no Decreto $5.297^{26}$, reduzindo tributos federais (PIS/PASEP/Cofins) aos produtores de biodiesel e estabelecendo diferentes percentuais em relação às regiões e ao selo combustível social, podendo chegar até a uma renúncia total ao produtor de biodiesel de Palma e Mamona, com selo nas regiões

24 Ministério da Ciência e Tecnologia, Selo Combustível Social. http://www.biodiesel.gov.br/acesso em 24/04/2007.

${ }^{25}$ BNDES, Programas, Biodiesel, http://www.bndes.gov.br/programas/infra/biodiesel.asp acesso em 03/03/2006

${ }^{26}$ Ministério das Minas e Energia, Consultoria Jurídica.

http://www.mda.gov.br/saf/arquivos/0761210027.pdf acesso em 03/03/2006. norte e nordeste; da renúncia de $89,6 \%$ aos produtores com o mesmo selo e que produzam em qualquer região com qualquer matéria prima; da redução de $77,5 \%$ aos produtores que não tem o selo, mas que se situam nas mesmas condições do grupo que tem total isenção e, da renúncia de $67 \%$ ao grupo sem selo e que produza em qualquer região, com qualquer matéria prima.

Tabela de renúncia fiscal

\begin{tabular}{|c|c|c|}
\hline \multirow{2}{*}{$\begin{array}{c}\text { Modalidade de produtor de } \\
\text { biodiesel }\end{array}$} & \multicolumn{2}{|c|}{ Matéria-prima / Região } \\
\cline { 2 - 3 } & $\begin{array}{c}\text { Qualquer matéria-prima qualquer } \\
\text { região }\end{array}$ & $\begin{array}{c}\text { Palma e Mamona (norte e } \\
\text { nordeste) }\end{array}$ \\
\hline Sem selo combustível social & $\mathrm{R} \$ 0,22(67 \%$ red) & $\mathrm{R} \$ 0,15$ (77,5\% red) \\
\hline Com selo combustível social & $\mathrm{R} \$ 0,07(89,6 \%$ red) & $\mathrm{R} \$ 0,00(100 \%$ red) \\
\hline
\end{tabular}

Fonte: Ministério da Ciência e Tecnologia. Redução de Tributos Federais ${ }^{27}$.

Com este fantástico aparato estatal do PNPB, mobilizando em grande escala, importantes recursos públicos para atingir os objetivos propostos no referido Programa, nos permitimos, sob a ótica da educação ambiental, resultante de um processo histórico que busca compreender as ações e reflexões humanas em suas relações sócio-ambientais, realizar alguns questionamentos que poderão contribuir para melhor compreendermos o Programa do Biodiesel.

Em relação ao aspecto da inclusão social enfocado nos objetivos do Programa, destacamos uma expressão de nosso presidente, Lula, divulgado no Jornal Diário do Nordeste:

[Lula] em vez de termos 300 mil hectares de mamona ou soja de um só produtor, é melhor pegarmos os pequenos produtores, que têm dois hectares, e incentivá-los a produzir mamona, girassol. Aí, a gente garante um salário extra para o pequeno produtor e vai melhorando a vida da região ${ }^{28}$.

\footnotetext{
${ }^{27} \mathrm{http}: / /$ www.biodiesel.gov.br/ acesso em 24/04/2007.

Diário do Nordeste. Biodiesel é a esperança do Nordeste, (JC e-mail 3196), http://www.jornaldaciencia.org.br acesso em 01/02/2007.
} 
O primeiro aspecto do texto, diz respeito ao problema de concentração fundiária no Brasil o qual trataremos mais adiante, com referência a produção pelos pequenos produtores para poder atender a demanda exigida em lei para o biodiesel, o Núcleo de Assuntos Estratégicos da Presidência da República revela o seguinte:

Segundo dados de 2002, a cultura de mamona no país é pequena 130.000 ha, constituindo-se principalmente de pequenas unidades de 15 ha.,. Se considerarmos um programa de substituição a $1 \%$ do óleo diesel seria preciso multiplicar por oito a produção atual. Teoricamente, isto é possível, mas neste nível tratar-se-ia de um programa muito mais voltado a atender aspectos sociais do que a necessidade de energia ${ }^{29}$.

Destaca-se, portanto, que a prioridade é a produção de energia e no que diz respeito à produtividade da mamona, o mesmo Núcleo ao colher dados da Embrapa, apresenta os seguintes dados:

[mamonas] apresentam produtividade anual de até $1.400 \mathrm{Kg} / \mathrm{Ha}$. se plantadas em áreas com zoneamento e estudo de época para plantio, feito pela Embrapa para o nordeste do país. Observações atuais, feitas por técnicos da Embrapa, indicam colheitas de 500 a 800 $\mathrm{Kg} / \mathrm{ha} / \mathrm{ano}$ por pequenos produtores da Paraíba, em condições normais de cultivo, e de cerca de 1.200 a $1.300 \mathrm{Kg} / \mathrm{ha} / \mathrm{ano}$ em plantios comerciais da Bahia $^{30}$.

As informações consideram a baixa produtividade da mamona em condições normais de cultivo, só conseguindo aumentar esta produção mediante aplicação de recursos técnicos que envolvem necessariamente uma ampliação dos custos de produção. Os interesses governamentais em amparar a produção familiar são extremamente louváveis do ponto de vista social, mas como expressou o NAE, a preocupação fundamental é produzir energia. Quanto ao risco destes agricultores serem controlados pelas grandes empresas é objeto de preocupação por alguns setores da sociedade.

Experiências como a plantação da mamona por pequenos agricultores no Nordeste demonstraram o risco de dependência a grandes empresas agrícolas, que controlam os preços, o processamento e a

${ }^{29}$ Cadernos NAE 2. Biocombustíveis, (Núcleo de Assuntos Estratégicos da Presidência da República) Brasília, NAE, 2004, p.13.

${ }^{30}$ Idem, p.45. distribuição da produção. Os camponeses são utilizados para dar legitimidade ao agronegócio, através da distribuição de certificados de "combustível social" 31 .

Acrescente-se a este risco de controle da produção o alto custo para a fabricação do biodiesel, necessitando-se industrializar o álcool, a soda cáustica e a montagem de laboratórios exigindo investimentos elevados, assim os pequenos produtores teriam que comercializar os seus produtos com grandes usinas ou a Petrobras. Com relação aos interesses explícitos das grandes empresas na produção do biodiesel podemos aferir através das informações a seguir, os seus graus de domínio: na pesquisa, na produção e comercialização do referido combustível.

Todas las empresas que producen cultivos transgénicos Syngenta, Monsanto, Dupont, Dow, Bayer, BASF tienen inversiones en cultivos diseñados para la producción de biocombustiblescomo son el etanol y el biodiesel. Tienen, asimismo, acuerdos de colaboración en este rubro con Cargill, Archer Daniel Midland, Bunge, trasnacionales que dominan el comercio mundial de granos. En la mayoría de los casos, la investigación se orienta a obtener nuevos tipos de manipulación genética de maíz, caña de azúcar, soya, entre otros, conviertiéndolos en cultivos no comestibles, lo cual aumenta dramáticamente los riesgos que ya conlleva en sí la contaminación transgénica ${ }^{32}$.

Destaca-se aí, não somente os interesses das transnacionais neste mercado, mas também o risco da ampliação do plantio de transgênicos, pois a justificativa de que estes grãos seriam consumidos só por máquinas, não elimina o perigo da contaminação do meio ambiente por estes elementos manipulados geneticamente.

Uma outra referência sobre o domínio destas grandes corporações neste mercado criado pelo Programa governamental revela que a preferência para a produção familiar, está sendo desviada, pois não é para a pequena propriedade que se dirige o controle da produção:

O grupo agrícola [Agrenco], criado há 15 anos na França e com sede na Holanda, é especializado nas áreas financeira, de comercialização,

\footnotetext{
${ }^{31}$ PINTO, Edivan e outros. O Mito dos biocombustíveis.

32 RIBEIRO, Sílvia. Biocombustibles y Transgénicos, http://www.jornada.unam.mx/2006/ 11/23/index.php?section=opinion\&article=024a2pol acesso 26/03/2007
} 
tecnologia e logística. O mais novo negócio é o biodiesel. Em sociedade com o grupo japonês Marubeni, a Agrenco está à frente de um dos maiores projetos de biodiesel anunciados até agora no país. Em dois anos, suas três usinas - duas em Mato Grosso e uma no Paraná - deverão atingir produção de 380 milhões de litros por ano de biodiesel feito a partir de soja, outras oleaginosas e gordura animal $^{33}$.

Para termos uma idéia da dimensão deste projeto, só este grupo tem como perspectiva a produção da metade da quota de $2 \%$ de biodiesel, prevista para o ano de 2008. Mas existem outros grupos interessados, vejamos:

Esse é um projeto espetacular. A gente vai produzir na 'porta da cozinha' e não vai pagar imposto, pois não se trata de uma operação comercial. Isso gera eficiência e competitividade para o agronegócio brasileiro', diz Maeda (empresário Jorge Maeda presidente do grupo Maeda). Os grandes agricultores não querem ficar de fora. O Grupo Amaggi, maior produtor de soja do país, está fazendo estudo de viabilidade econômica do negócio ${ }^{34}$.

Este grupo se localiza no estado do Mato Grosso, quanto ao nordeste, no vale do Rio São Francisco:

Cinco projetos de irrigação administrados pelo governo federal ao longo do rio São Francisco serão convertidos no mais novo pólo de produção da matéria-prima utilizada na fabricação de açúcar, álcool e biodiesel 100\% vegetal. A Companhia de Desenvolvimento do Vale do São Francisco (Codevasf) aposta que os aportes de grandes grupos nacionais e multinacionais na construção de novas usinas vão migra para as áreas, consideradas as últimas fronteiras de terra barata e água abundante para a produção de cana irrigada no país ${ }^{35}$

Desta forma com terra e mão-de-obra barata, irrigada com os recursos do tesouro nacional, com financiamento facilitado, com renúncia

${ }^{33}$ CANÇADO, Patrícia. Biodiesel atrai grandes grupos e investimentos de $\mathrm{R} \$ 1,2$ bilhão, $O$ Estado de SP, 19/03/2007, (JC e-mail 3225), http://www.jornaldaciencia.org.br acesso em $19 / 03 / 2007$

${ }^{34}$ Mato Grosso será o maior produtor do combustível, O Estado de SP, 19/03/007. (JC email 3225), http://www.jornaldaciencia.org.br acesso em 19/03/2007.

35 ZANATTA, Mauro. Um plano para fazer do sertão um mar de cana, Valor Econômico, 12/02/2007, (JC e-mail 3204), http://www.jornaldaciencia.org.br acesso em 12/02/ 2007 (grifo nosso). fiscal e garantia de mercado consumidor, quais seriam os riscos das grandes corporações empresariais que dizem preferir liberdade de mercado para prosperar ao invés de seu controle pelo aparato do Estado?

O Programa governamental que pressupõe a inclusão social, a reincorporação de terras degradadas pela agropecuária extensiva, a diversificação de sementes: mamona, pinhão manso, girassol, amendoim, babaçu, dendê e soja, expressam outros fatores que nos alertam para analisá-lo de forma interdisciplinar e profunda.

Por exemplo, em relação à diversidade de uso de sementes:

A soja, que avança sobre a floresta e concentra terras, caminha para dominar a matriz do biodiesel nacional. [...]. A empresa Brasil Ecodiesel, uma das pioneiras do programa, que é apoiada pelo governo, já tem o óleo de soja como sua matéria-prima principal, apesar de ter nascido com o objetivo de explorar a mamona. Os empresários do agronegócio, a maioria instalados no Centro-Oeste, esperam fornecer $90 \%$ da matéria-prima para o biodiesel brasileiro. A estimativa do governo é que esse grão não passe dos $60 \%$. Segundo o presidente da Embrapa, a conta é a seguinte: "Nos próximos 30 anos será necessária a produção de 100 bilhões de litros de biodiesel. E, para isso, vamos precisar de 40 milhões de hectares." Ele mesmo indica o obstáculo que precisa ser transposto. "A questão pega no investimento. Para recuperar 20 milhões de hectares pouco produtivos são necessários $\mathrm{R} \$ 40$ bilhões. Ainda está mais barato derrubar floresta ${ }^{36}$

É o próprio presidente da Empresa Brasileira de Pesquisa Agropecuária que considera o monopólio da soja, o domínio do agronegócio e a tendência na expansão da cultura de grãos sobre a floresta. A Petrobras também priorizou a soja como a semente que fornecerá o óleo para misturar ao petrodiesel no processo de refinamento do mesmo, o " $\mathrm{H}$ Bio", que difere do biodiesel por este significar a mistura de ambos óleos nas distribuidoras de combustíveis.

Como fica então a diversidade da produção de grãos, a ênfase no apoio as pequenas propriedades, a recuperação de terras degradadas? Quebrou-se a varinha de Condão?

${ }^{36}$ CRESTANA, Sílvio. Questão de Cultura. Folha de SP, 21/01/2007, (JC e-mail 3188), http://www.jornaldaciencia.org.br acesso em 22/01/2007. 
Quanto à eficiência energética da soja, ela é segundo Weber Amaral, diretor do pólo nacional de biocombustíveis uma das piores opções, pois só rende $18 \%$ de óleo, tendo ainda, gasto na sua produção, um quarto do teor energético que foi consumido para cultivá-la ${ }^{37}$. Podemos agregar a este argumento outros dados: para cada 2 bilhões de litros de biodiesel produzidos, metade, 1 bilhão de litros é de água usada no processo e que precisaria ser recuperada. Deve também ser incorporado ao custo da produção do biodiesel o uso do álcool para a sua fabricação:

Para produzir mil litros de biodiesel, as usinas incorporam atualmente no processo de produção até 300 litros de metanol. Na fabricação com etanol, esse número sobe ao patamar de 500 litros do álcool feito no Brasil de cana-de-açúcar. Nos dois processos, no entanto, sobra cerca de $50 \%$ de qualquer um dos álcoois, num processo chamado de recuperação do excesso que leva a parte que sobra ao início da produção ${ }^{38}$.

Os dados apresentados consideram, portanto, que para a produção de mil litros de biodiesel, são gastos pelo menos e de forma definitiva, 150 litros de metanol ou 250 litros de etanol, isto é um custo que deve ser incorporado ao valor final do biodiesel.

A eficiência econômica da soja também pode ser questionada, tendo em vista que, em 2006 a soja registrou uma renda agrícola de $\mathrm{R} \$ 22.1$ bilhões, 13\% abaixo do ano de 2005 e, $40 \%$ abaixo do ano de 2003, gerando uma crise de liquidez e renda no setor fazendo que uma série de medidas econômicas fosse adotada pelo tesouro nacional que lhe custou R \$ 20 bilhões39. Poderíamos dizer que isto significa uma socialização dos prejuízos, mas quando ocorre o lucro, o mesmo é privatizado. Ampliação e concentração das terras, máquinas, equipamentos e outros bens que são resultantes desta privatização por parte dos grandes empresários do agronegócio.

\footnotetext{
${ }^{37}$ GERARQUE, Eduardo. Embriaguez bioenergética, Folha de SP 21/01/2007, (JC email 3188), http://www.jornaldaciencia.org.br acesso em 22/01/2007.

${ }^{38}$ OLIVEIRA, Marcos de. Biodiesel em ascensão, Revista Fapesp, Fapesp/, São Paulo, n.134, 2007, p.63.

${ }^{39}$ LOPES, Fernando. Na onda da bioenergia. Valor Econômico 8/12/2006 (JC e-mail 3159) http://www.jornaldaciencia.org.br acesso em 08/12/2006.
}

Assim o Programa do governo federal deveria prever, planejar, coordenar e intervir na estrutura econômica e fundiária para que houvesse verdadeiramente um Programa de inclusão social da agricultura familiar como fundamento básico da segurança nacional pela incorporação de cidadãos na sociedade brasileira.

Ao invés disso o Brasil ocupa o segundo lugar de concentração fundiária e o primeiro lugar de desigualdade de renda no mundo ${ }^{40}$.

Vejamos estes dados, que não estão escondidos como coelhos em cartola e nos são fornecidos pelos organismos oficiais do governo federal:

\section{Concentração Fundiária - Índice de Gini - INCRA e IBGE ${ }^{41}$}

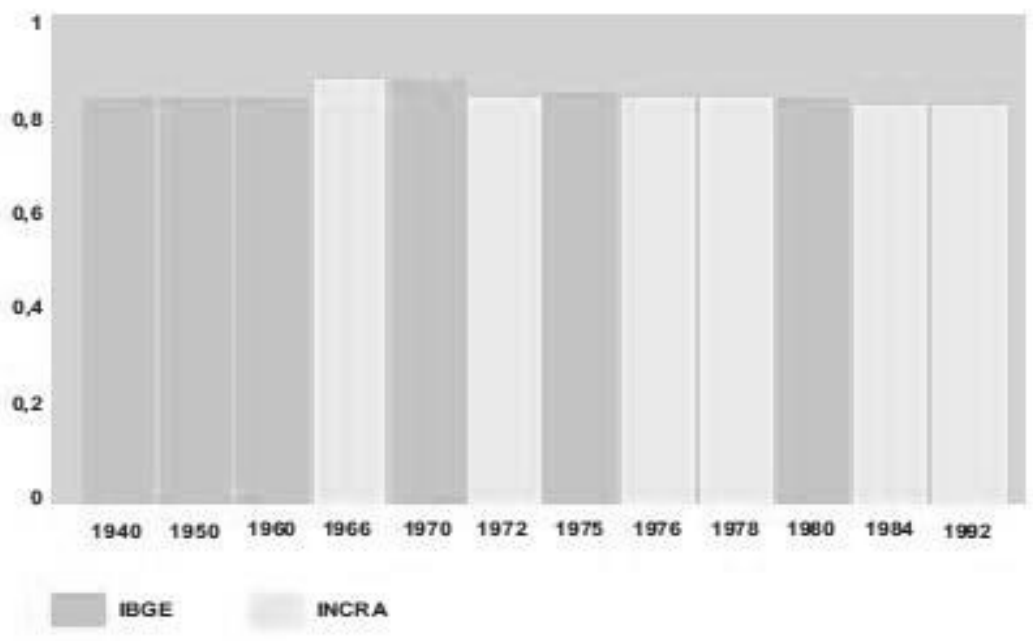

O Índice de Gini é uma medida do grau de desigualdade da distribuição de renda ou de um recurso. $\mathrm{O}$ índice varia de um mínimo de

\footnotetext{
${ }^{40}$ SILVA, Lígia Maria O. Terra, direito e poder - O latifúndio improdutivo na legislação agrária brasileira. BOLETIM ABA (27)

http://www.unicamp.br/aba/boletins/b27/04.htm\#Terra,\%20direito\%20e\%20poder acesso em 03/05/2007.

${ }^{41}$ Governo Federal. A reforma agrária no Brasil.

https://www.planalto.gov.br/publi_04/COLECAO/REFAGR3.HTM acesso em 03/05/2007.
} 
zero a um máximo de um. "Zero" representa nenhuma desigualdade e "um" representa grau máximo de desigualdade.

Como um Programa governamental da magnitude do biodiesel não leva em conta estes dados que explicitamente detectam o domínio dos grandes latifundiários, os quais com sua força econômico-política podem açambarcar em proveito próprio os apoios financeiros, fiscais, científicos e tecnológicos provenientes dos recursos públicos? As diferenças nas taxas de juros de empréstimos e renúncia fiscal aos produtores que tem o Selo Social não expressam um apoio significativo para a inclusão social da agricultura familiar. No entanto, estimulam os grandes empreendimentos beneficiandoos por este apoio e contribuindo para o aumento na concentração fundiária.

Nem a experiência histórica da produção de um outro biocombustível, o álcool pelo Pro-alcool é ponderada para se detectar a condição da evidente concentração fundiária, a degradação ecológica, a condição de miserabilidade dos cortadores de cana. Um Programa governamental deveria ao menos realizar um balanço destes problemas e estabelecer mecanismos de prevenção e correção dos mesmos. Mas isso não ocorreu, e como expressa o Núcleo de Assuntos Estratégicos da Presidência da República: o importante é a produção de energia. Não há indagações críticas de como a energia será produzida, quais os seus produtores, como será usada, para atender a quais setores, alternativas estratégicas, contraprodutividade energética, dispêndio de energia na sociedade brasileira, programas de eficiência energética?

Quais foram os resultados benéficos da agroindústria sucro-alcoleira aos trabalhadores da cana, a distribuição da propriedade, a preservação dos mananciais, das florestas, ao assentamento rural, a diminuição da criminalidade na periferia das cidades, a saúde pública, a segurança pública, enfim a distribuição de renda no país?

Evidentemente que o cálculo não possui apenas estes elevados custos sócio-ecológicos, mas também apresenta resultados favoráveis quanto à existência de uma alternativa energética ao uso do petróleo, a construção de uma tecnologia nacional de produção de etanol, ao aperfeiçoamento de motores e equipamentos, a geração de pesquisa agropecuária no setor da cana-de-açúcar, a uma diminuição de vapores tóxicos expelidos por estes motores, a geração de divisas para o país, principalmente para os grandes latifundiários produtores de biocombustíveis, que estão se colocando em uma situação competitiva no concorrido mercado internacional de produção de combustíveis.

Não se trata de uma análise maniqueísta e, nem de se fazer uma apologia, calibrada com frases de efeito dos fantásticos poderes do biodiesel, representando simbolicamente o magistral e inaudito feito de como: "Sir Lancelot retirou Excalibur da rocha, para empurrar Argus às profundezas do inferno e amarrá-lo com o Nó Górdio, solucionando assim os intrincados problemas sócioambientais.” Este feito lendário nunca antes relatado, agora ganha historicidade literária, existência textual, fazendo jus à famosa frase: "Papel aceita tudo!"

O que estamos buscando com este curto trecho que evoca uma fantasia literária, é chamarmos a atenção para a necessidade de uma análise mais pormenorizada do Programa, buscando-se ponderar sobre dados existentes para se estabelecer uma política de eficiência sócioecológica para a sociedade, evitando a realização de elogio deslumbrado, como o que foi feito em homenagem aos usineiros, designando-os como "heróis"42. Logo após, de forma contraditória em relação a este pronunciamento governamental divulgado em imprensa internacional, o presidente Lula se expressa em artigo sobre as condições de trabalho dos colhedores de cana:

Realmente, as condições de trabalho dos colhedores de cana precisam ser melhoradas, e nós estamos plenamente empenhados nessa tarefa. Entretanto, essa questão não justifica críticas ásperas a uma atividade econômica que oferece empregos e esperança a tantas pessoas no Brasil e pelo mundo inteiro ${ }^{43}$

Deduz-se então, que o primordial é o oferecimento de empregos, relegando o problema da concentração fundiária e as condições degradantes destes empregados, que se equiparam a vida útil dos escravos, por suas condições de existência nas periferias das cidades, por sua nutrição e pela estafante jornada de trabalho. Supõe-se que, desde 2004, dezenove mortes

\footnotetext{
${ }^{42}$ Folha Online. Presidente Lula chama usineiros de heróis. http://www1.folha.uol.com.br/ folha/brasil/ult96u90477.shtml acesso em 20/03/2007.

${ }^{43}$ SILVA, Luiz Inácio Lula da. Nossa parceria em bicombustíveis, Washington Post e Estado de SP, (JC e-mail 3235), http://www.jornaldaciencia.org.br acesso em 02/04/2007.
} 
ocorreram por excesso de trabalho nos canaviais do Estado de São Paulo, considerado o estado mais rico e desenvolvido da federação ${ }^{44}$.

Movimentos sociais que se preocupam com as condições de trabalho no campo, apresentaram análises críticas em relação ao modelo de produção de bioenergia, considerando que é o mesmo modelo que há centenas de anos vem causando opressão social pela concentração de terras, renda e lucro, apropriando-se e super-explorando a força de trabalho ${ }^{45}$. Considerando ainda a necessidade de se analisar criticamente a matriz energética nacional, que em seu setor de transportes é o maior consumidor de petróleo e biocombustíveis e re-orientando a produção de alimentos de animais e seres humanos, para motores de caminhões e $\operatorname{carros}^{46}$.

As máquinas agora, realizam uma considerável atividade de trabalho que podem permitir ao ser humano, desfrutar de seu tempo para a realização de trabalho menos extenuantes e de lazer, mas nas atuais condições sociais de produção, trabalhadores morrem extenuados pelo esforço físico empreendido para sua sobrevivência e, se pelo menos, até há pouco tempo, as máquinas não eram diretamente nossas concorrentes em relação aos alimentos, agora elas estão consumindo os nossos alimentos.

Estabelece-se uma contra-produtividade energética ao fornecermos alimentos (cana, soja, milho) que podiam ser sintetizados pelos nossos organismos, a animais confinados (bovinos, equinos, aves, suínos) que possuem condições orgânicas de sintetizar alimentos (grama) que não metabolizamos, e que a partir da carne, leite e ovos, destes animais poderíamos usufruir, realizando desta forma uma otimização energética, agora, a concorrência mecânica multiplicou de forma descomunal a sua força.

Não estamos mais sentados na mesma mesa, dividindo um prato de soja com um boi de uma tonelada, mas estamos dividindo o mesmo prato,

${ }^{44}$ ZAFALON, Mauro. Cortadores de cana têm vida útil de escravo em SP, Folha de São Paulo, 29 de abril de 2007. B.1.

Manifesto da Via Campesina. Tanques cheios às custas de barrigas vazias. http://www.brasildefato.com.br/v01/agencia/especiais/especial.2007-03-

06.3252786579/tanques-cheios-as-custas-de-barrigas-vazias acesso em 07/03/2007.

${ }^{46}$ Carta Maior. Movimentos aprovam combustíveis vegetais com ressalvas, diz Stédile. http://agenciacartamaior.uol.com.br/templates/materiaMostrar.cfm?materia_id=13641 acesso em 05/03/2007 com um motor diesel de quatrocentos cavalos de força (horse power) e, isto está sendo considerado como a produção energética ecologicamente sustentável! Estamos alimentando carros, de aproximadamente uma tonelada de peso, possuindo em média $90 \mathrm{HP}$, consumindo em média 8 litros de combustível por $\mathrm{km}$, agregando uma imensa quantidade de energia e matéria na sua produção e para o seu uso (estradas, pontes, viadutos, garagens), com capacidade de carga de até 5 pessoas, para transportar em grande parte de sua vida útil de rápida degradação, apenas uma pessoa. A fabricação do biodiesel, ou do álcool é para atender a esta atividade e, se já tínhamos críticas em relação a sua produção, o uso dos referidos biocombustíveis deve também ser questionado.

No que diz respeito à produção e consumo de alimentos para a população mundial:

Pode o "planeta" alimentar a sua população atual, ou seja, 6 bilhões de habitantes, com as colheitas atuais? Essa questão não tem fundamento, pois ela depende do que significa "alimentar". Se isso quer dizer que a produção de alimentos seria dividida de maneira que todo o mundo recebesse uma ajuda de custo idêntica em grãos e tubérculos, com um mínimo de proteínas provenientes de ervilhas, feijão e de leguminosas para mal atingir a taxa necessária de 2.350 calorias por dia, então a resposta para ela é sim. Em um contexto de igualdade absoluta e de vontade universal em que cada um se contentasse com uma dieta básica, respectiva e de sobrevivência, o planeta poderia efetivamente alimentar a sua população atual e até mesmo um pouco mais. Por outro lado, se isso significa que um quarto do regime de cada um é composto de produtos de origem animal (que são "concentrados de calorias") e que as pessoas podem também consumir frutas, legumes e azeites (e, de nossa posição privilegiada, acrescentaríamos de bom grado o vinho e a cerveja), então a nossa resposta é, definitivamente, não ${ }^{47}$.

Considera-se, portanto, que o planeta possui capacidade de prover a todos os seres humanos a quantidade fundamental de calorias, desde que, haja uma distribuição igual das mesmas, no entanto, isso não ocorre, devido à distribuição desigual de poder e recursos, entre os países e entre os seres humanos, para tornar mais dramático esta questão, acrescente-se a este

${ }^{47}$ GEORGE, Susan. O relatório Lugano: Sobre a manutenção do capitalismo no século XXI, trad. Afonso Teixeira Filho, São Paulo: Boitempo, 2003, p.133. 
problema a necessidade criada socialmente, dos proprietários de veículos terem que alimentá-los com óleo comestível. Será que vai ter biocombustível com óleo de oliva, para aqueles que querem um aditivo especial em suas poderosas e reluzentes máquinas?

Em um mundo onde, de acordo com as Nações Unidas, 1 bilhão de pessoas sofre de fome crônica e má nutrição, e 24 mil morrem diariamente de causas relacionadas a esses problemas - entre estes, 18 mil são crianças -, faz-se necessário questionar se as terras do planeta se destinarão preferencialmente a atender aos cerca de 800 milhões de proprietários de automóveis, ou à garantia da segurança alimentar mundial. E mais, se o Sul continuará a desempenhar o papel de fornecedor da matéria prima necessária para possibilitar ao Norte manter seu padrão de consumo ${ }^{48}$

Alguns argumentos consideram que os biocombustíveis não prejudicaram o consumo alimentar dos pobres, pois estes não comem porque não possuem emprego, assim, com a inclusão social promovida pelo Programa do biodiesel os marginalizados socialmente poderiam alimentarse com os recursos econômicos oriundos do processo de crescimento econômico dirigido pelo sentido do desenvolvimento sustentável embasado na matriz energética da biomassa renovável. Ora estamos notando, que a inclusão social é tão falsa que até Pinóquio ficaria enrubescido em sua "cara de pau", que a proteção dos recursos naturais é uma casa de palha, facilmente destruída pelo sopro do "Lobo Mau", que o uso ecologicamente correto dos biocombustíveis é uma estória para "ninar bovinos na invernada".

Como fica então o argumento da necessidade de crescimento econômico voltado para a produção intensiva de produtos para atender o mercado consumidor? Quanto mais produzimos mais degradamos, por causa da entropia, dissipação energética? Quanto mais incorporamos a população carente nos hábitos do consumo do mercado capitalista, mais aumentamos a exploração sobre os recursos ambientais e mais aumentamos os resíduos deste processo? Quanto mais intensificamos o consumo de uma mercadoria, ela poderá se tornar mais cara pela sua raridade? Os alimentos

${ }^{48}$ GLASS, Verena. Diante da fome e da escassez de água, o que significa plantar energia, Agência Carta Maior.

http://agenciacartamaior.uol.com.br/templates/materiaMostrar.cfm?materia_id=13631\&bolet im_id=240\&componente_id=4558 acesso em 03/03/2007. não sofrerão um acréscimo no seu custo por concorrem com a produção do combustível? Os usineiros de álcool e açúcar direcionam a sua produção e comercialização de seus produtos de acordo com os valores oferecidos pelo mercado? Este fator de liberdade empresarial para direcionamento da produção pode gerar um desabastecimento nacional, pois empresas buscam lucro atendendo os valores mais altos oferecidos no mercado? $\mathrm{O}$ aumento de quase $400 \%$ no preço do milho, principal alimento dos mexicanos, foi ocasionado pela exportação deste produto para atender a produção do álcool estadunidense? Se o Brasil foi recentemente elevado à sétima posição na economia mundial, possuindo uma das mais altas concentrações de riqueza do mundo, a possibilidade de aprimorar a condição de vida da sua população estaria na melhor distribuição e utilização destes recursos?

O nosso processo de crescimento econômico foi e é também o processo de concentração de riqueza, onde se excluiu a cidadania como valor de pertencimento a coletividade e privilegiou-se o consumidor, sendo que, alguns são mais consumidores que outros, e que muitos dentre estes, só lhes restou à possibilidade de consumirem a fantasia publicitária, assim: "Se o crescimento econômico não é sustentável e se a racionalidade econômica não contem os mecanismos para sua desativação, então é necessário construir outra racionalidade produtiva que possa operar conforme os princípios da sustentabilidade" ${ }^{, 49}$.

A justificativa da manutenção deste modelo de produção pode servir para a manutenção de empregos em fábricas de armas, de automóveis. Mas a questão fundamental da construção de uma sociedade sustentável está ligada às condições de possuirmos os nossos meios de sobrevivência autônoma, implicando diretamente na utilização ecológica da distribuição social dos bens patrimoniais de nossa nação, sejam estes culturais e ambientais. O questionamento sobre a noção de sustentabilidade pressupõe a necessidade de se analisar os mecanismos de organização sócioeconômica de nossa sociedade que entende como modelo de referência de desenvolvimento um crescimento exponencial do consumo de energia e matéria, sem analisar detidamente a que setores ela atende, de que forma é produzida colocando em risco a biodiversidade, os ecossistemas e o planeta. ${ }^{49}$ LEFF, Enrique. Racionalidade Ambiental: a reapropriação social da natureza. Trad. Luís
Carlos Cabral, Rio de Janeiro: Civilização Brasileira, 2006, p.232 (grifo do autor). 
Nota-se, ao se analisar o consumo dos recursos naturais no mundo, a diferença deste consumo entre os países: "No que respeita à promessa de igualdade os países capitalistas avançados com $21 \%$ da população mundial controlam $78 \%$ da produção mundial de bens e serviços e consomem $75 \%$ de toda a energia produzida." 50 No interior dos países este consumo é distribuído de forma desigual, por exemplo, no Brasil, segundo pesquisa do Instituto Brasileiro de Geografia e Estatística, quase 14 milhões de pessoas passam fome ${ }^{51}$, no entanto, nosso índice do Produto Interno Bruto está entre os maiores do mundo, demonstra-se assim, mais uma vez, a péssima distribuição da riqueza.

Podemos considerar que os países desenvolvidos consomem muito mais do que o estoque de recursos naturais que possuem em seus próprios territórios, assim ao importarem estes recursos de outros países, estão de certa forma, ampliando o seu território sem necessariamente estabelecer presença física com seus exércitos. A globalização expressa novas formas de colonialismo, exportação de fábricas poluentes, importação de energia sob forma de petróleo, óleo, a biopirataria na Amazônia, ou as transnacionais nos campos e nas indústrias produzindo as desejadas máquinas inebriantes:

Viajo num automóvel novo. Sinto a sua beleza, seu brilho, sua potência, sua conveniência - mas então me apercebo do fato de que dentro de um prazo relativamente curto ele se deteriorara e necessitará de reparos: de que sua beleza e superfície são ordinárias, sua potência desnecessária, seu tamanho uma idiotice; e de que não encontrarei um local para o estacionamento. [...]. Eu me sinto de certo modo ludibriado ${ }^{52}$.

Bem como o álcool e o petróleo, produziremos biodiesel para alimentarmos o nosso sistema de transporte de elevado consumo energético e de extrema ineficácia energética.

Como um sucedâneo do óleo diesel, o mercado potencial para o biodiesel é determinado pelo mercado do derivado de petróleo. A

\footnotetext{
${ }^{50}$ SANTOS, Boaventura de Sousa. A crítica da razão indolente: contra o desperdício da experiência, São Paulo: Cortez, 2000, pp.23-24.

51 Folha Online. Quase 14 milhões de pessoas passam fome no Brasil, diz IBGE. http://www1.folha.uol.com.br/folha/dinheiro/ult91u107755.shtml acesso em 17/05/2006.

52 MARCUSE, Herbert A ideologia da sociedade industrial. Rio de Janeiro: Zahar, 1967, p. 210 .

demanda total de óleo diesel no Brasil em 2002 foi da ordem de 39,2 milhões de metros cúbicos, dos quais $76 \%$ foram consumidos no setor de transporte, $16 \%$ no setor agropecuário e $5 \%$ para geração de energia elétrica nos sistemas isolados. [...] No setor de transporte, 97\% da demanda ocorre no modal rodoviário, ou seja caminhões, ônibus e utilitários, já que no Brasil estão proibidos os veículos leves a diesel $^{53}$.

Poucos são os meios de transporte que escapam do uso destes combustíveis, por exemplo, trens, bondes, metrôs elétricos, possuindo desta forma uma elevada eficácia de consumo energético, isto é, transportar maior tonelagem, por quilômetro com menor consumo de energia. Não estamos preocupados neste trabalho em ampliar a comparação com outros meios de transporte como: barcos à vela, veículos de tração animal e bicicletas de excelente eficácia material e energética no uso urbano, porque estamos preocupados com o desafio de se transpor ongas distâncias, carregando grande quantidade de carga e em pouco tempo.

Quando comparamos, o consumo de diesel no setor de transporte rodoviário, com o seu consumo em outros setores como o ferroviário ou, o hidroviário, podemos notar estas expressivas diferenças:

Responsável pela movimentação de $62 \%$ das cargas, a malha rodoviária escoa apenas $20 \mathrm{ton} / \mathrm{km}$ por litro de diesel, enquanto os sistemas ferroviário e hidroviário, que juntos respondem por $34 \%$ da carga do setor, podem realizar um trabalho de mais 150 ton $/ \mathrm{km}$ por litro de diesel ${ }^{54}$.

Porque estes dados comprovadores da ineficácia de consumo energético não são ponderados no PNPB, que prioriza a produção do biodiesel, complementando o diesel, utilizado predominante no transporte rodoviário? Estudos com esta preocupação foram já foram apresentados, Ignacy Sachs, por exemplo, considera que a produção dos biocombustíveis é apenas parte de uma estratégia mais ampla, que têm como importância maior, a preocupação com a conservação e eficiência da energia, mas para isso se faz necessário mudar a estrutura de nossas cidades e nosso estilo de

\footnotetext{
${ }^{53}$ Biodieselbr.com, Biodiesel Brasil: Demanda Brasileira.

http://www.biodieselbr.com/biodiesel/brasil/biodiesel-brasil.htm acesso em 23/04/2007.

54 Patusco, apud MATTOZO, Vânia, Energia, ambiente e mídia: qual é a questão? Florianópolis: Ed. UFSC, 2005, p.84.
} 
vida, priorizando o sistema de transporte de massa e utilização de bicicletas e reduzindo o uso de carros individuais ${ }^{55}$.

Quais grupos, interesses e atitudes políticas e sócio-econômicas privilegiaram em nosso processo histórico, o meio de transporte rodoviário? Este meio é possuidor de alto potencial poluidor, de ineficaz consumo energético, de elevado risco de acidentes com despesas nos setores de saúde, previdenciário e social, com rápida obsolescência técnica, com prioridade ao transporte individual, com alta dependência tecnológica, enfim, podemos compreender como uma questão de segurança nacional, pela quase total ausência de alternativas de transporte no território brasileiro e pela enorme ineficácia de consumo de energia e matéria, nossos recursos naturais.

Visualizamos pelo gráfico a seguir, a amplitude do domínio do transporte rodoviário ${ }^{56}$, de carga ou de passageiros, entre outros meios de transporte:

Gráfico 1 - Participação dos segmentos no VP de transportes.

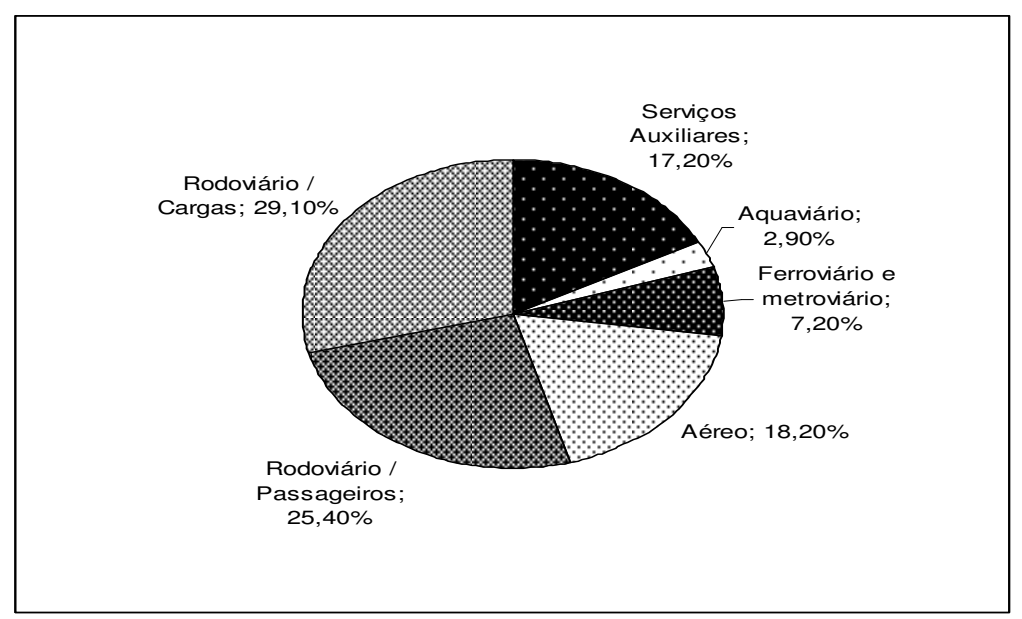

${ }^{55}$ SACHS, Ignacy. Expensive oil: for least developed countries a quiproquo of curse and blessing in disguise. IEA-USP. http://www.iea.usp.br/iea/biomassa/ artigosachsjan2006a.pdf acesso em 04/04/2006.

${ }^{56}$ Instituto Brasileiro de Geografia e Estatística. Pesquisa anual de serviços.

http://www.ibge.gov.br/home/estatistica/economia/comercioeservico/pas/analisepas $99 . s h t m$ acesso em 08/01/2007.
Podemos notar em relação a estes dados o predomínio do transporte rodoviário com $54,5 \%$; na sequência o setor aéreo com $18,2 \%$, índice que representa um elevado custo para um país com alto índice de concentração de renda. Com relação aos serviços auxiliares $17,2 \%$, não há nenhuma descrição de quais seriam estes serviços; ficando em penúltimo e último lugar respectivamente os característicos transportes de massa, 7,2\% metrô e trem e o, aquaviário com 2,9\% em contradição com a nossa elevada rede hídrica continental e costeira.

A tabela e gráficos a seguir, oriundos da secretaria de trânsito do Estado do Rio de Janeiro, continuam demonstrando a prioridade no transporte rodoviário e, a constatação do elevado consumo de diesel e gasolina, acompanhado de perto pelo álcool:

Tabela setores de transporte e tipos de combustível.

\begin{tabular}{|c|c|c|c|c|c|c|c|c|}
\hline Setor & $\begin{array}{c}\text { Total } \\
\text { Primária } \\
(1)\end{array}$ & Diesel & Gasolina & Querosene & Eletricidade & Álcool & Outros & Total \\
\hline $\begin{array}{c}\text { Consumo } \\
\text { final }\end{array}$ & 35101 & 25587 & 12740 & 2559 & 80293 & 6961 & 34012 & 197253 \\
\hline $\begin{array}{c}\text { Total } \\
\text { Transporte }\end{array}$ & 31 & 20385 & 12740 & 2481 & 365 & 6961 & 675 & 43638 \\
\hline Rodovias & 31 & 19647 & 12689 & 0 & 0 & 6961 & 0 & 39328 \\
\hline Ferrovias & 0 & 395 & 0 & 0 & 365 & 0 & 0 & 760 \\
\hline Aerovias & 0 & 0 & 51 & 2481 & 0 & 0 & 0 & 2532 \\
\hline Hidrovias & 0 & 343 & 0 & 0 & 0 & 0 & 675 & 1018 \\
\hline
\end{tabular}

A tabela mostra que o setor de transporte consumiu em 1996, 43 milhões de toe [toneladas equivalentes de petróleo] de energia, o que corresponde a $21 \%$ do consumo total do país. Dentro do setor de transporte, o transporte rodoviário é a forma predominante de uso de energia (90\% de 
toda a energia consumida no setor), como consequência das políticas de transporte adotadas nas últimas décadas ${ }^{57}$.

Se agregarmos os dados dos combustíveis: diesel, gasolina e álcool, veremos a sua quase que exclusiva utilização no setor de transporte rodoviário, considerando ainda que mesmo na ferrovia o diesel seja mais intensamente utilizado do que a energia elétrica considerada mais eficiente.

O gráfico em sequência apresenta as respectivas porcentagens de utilização das fontes energéticas no setor de transporte rodoviário e urbano no Brasil, no ano de 1996:

\section{Gráfico 2 - Consumo de energia no transporte - Brasil}

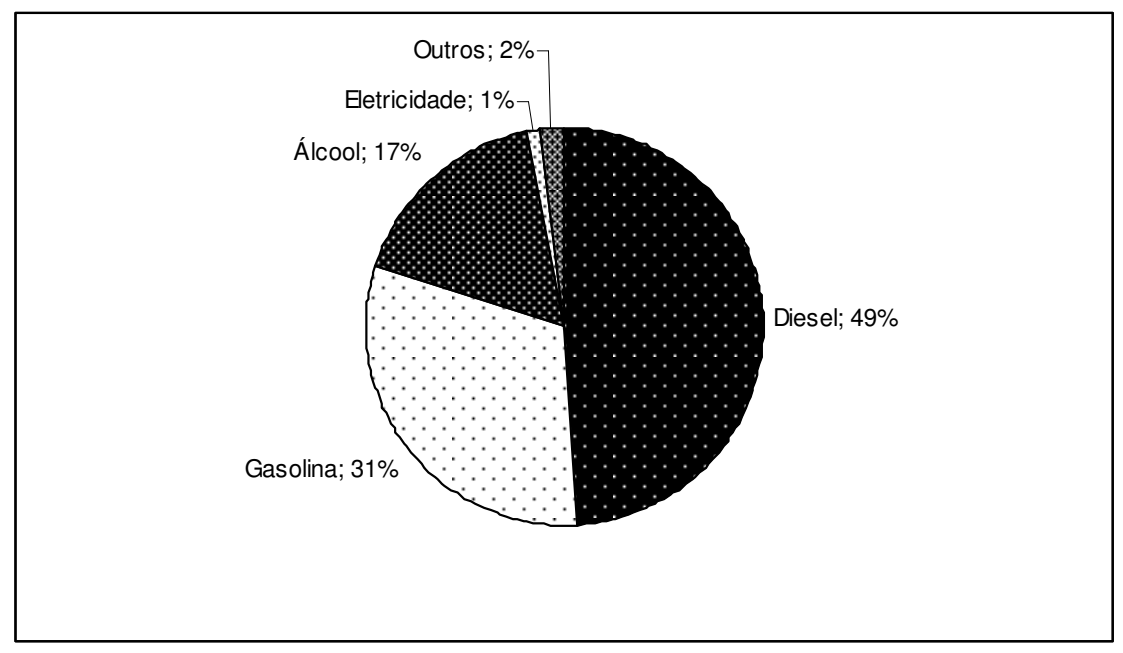

Ref.: Ministério das Minas e Energia

Ao contabilizarmos estes dados para efeito de demonstração, podemos notar o altíssimo risco estratégico que a nossa sociedade enfrenta, por depender tão essencialmente destas poucas fontes de combustíveis.

Em relação aos combustíveis não renováveis, diesel e gasolina o índice é de $80 \%$, somando com $17 \%$ do álcool renovável, resulta num total

${ }^{57}$ Secretaria de Trânsito do Estado do Rio de Janeiro.

http://www.sectran.rj.gov.br/saiva_meio_ambiente.asp 10/05/2006. de $97 \%$ do consumo destas fontes energéticas para a movimentação de todos os produtos e pessoas no país.

Este quase total monopólio de fonte energética infere diretamente na ausência estratégica de alternativas perante problemas de natureza conjunturais (guerras, revoluções) e estruturais esgotamento e poluição dos recursos naturais. Voltamos a insistir, este é um perigo de altíssimo potencial para o funcionamento de nossa sociedade.

O gráfico a seguir, demonstra uma progressiva elevação do consumo destes combustíveis há pelo menos vinte anos, não apresentando nenhuma tendência de queda por alguma substituição estratégica de combustíveis alternativos.

\section{Gráfico 3 Consumo de combustíveis no Brasil.}

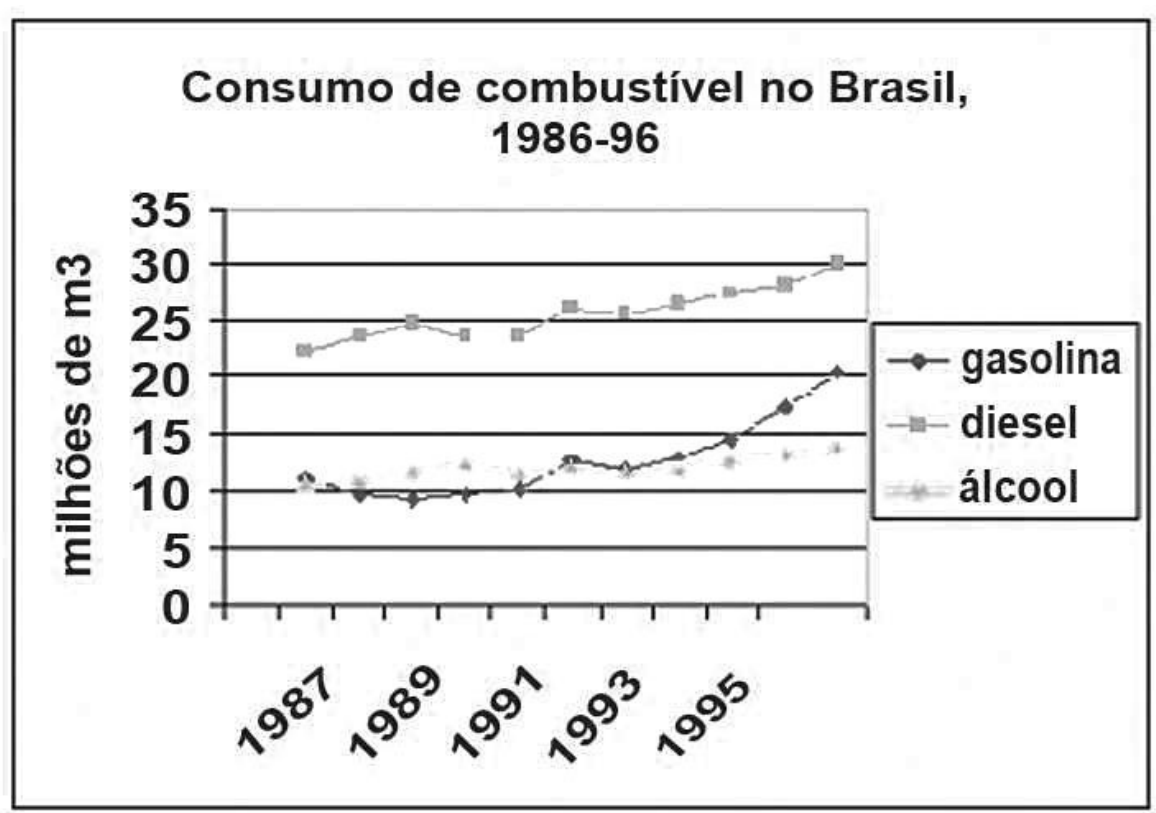

Ref.: Ministério das Minas e Energia

Considera-se que o biodiesel poderia compor uma alternativa ao problema anteriormente referido, por ser um combustível renovável, não 
poluente, de eficácia tecnológica para os motores e de inclusão social. No que diz respeito a sua eficácia de consumo, estudos estão demonstrando que por apresentar uma potência menor do que o petrodiesel, o consumo dos motores acaba aumentando ${ }^{58}$.

Em relação à diminuição de poluição, pela diminuição de $\mathrm{CO} 2$, não se pondera sobre as áreas de florestas abatidas gerando $\mathrm{CO} 2$ para a ampliação das culturas ${ }^{59}$; se despreza a elevação de 2 a $4 \%$ do NOx (Óxido de Nitrogênio) na queima do biodiesel, podendo gerar infecções e enfisema pulmonar; despreza-se também a, necessidade de purificação da água utilizada no processo de fabricação, como também não se computa a diminuição da biodiversidade pelo exercício da monocultura das sementes escolhidas.

Temos ainda, todos os riscos ambientais que envolvem a utilização de transgênicos na lavoura, com a justificativa que as sementes produzidas não seriam para consumo humano ou animal e, inclusive justificativas para uso insumos mais baratos:

Ao considerar que o agronegócio está focado nos mercados alimentícios e químicos, cujas especificações devem permitir o consumo humano, todos os fertilizantes, defensivos e reagentes devem ser nobres e, portanto, caros. Além de para o mercado de combustível isto não ser necessário, não é conveniente criar um núcleo competitivo com a produção de alimentos. O ideal é serem desenvolvidas plantações para este fim, usando componentes mais baratos e obtendo ganho de escala $[\ldots]^{60}$

Não há detalhes de quais fertilizantes, biocidas e reagentes seriam estes para baratear a produção, mas será que não poderiam provocar maiores danos ambientais? Com relação ao aproveitamento do resíduo da fabricação do biodiesel por óleo de fritura, um estudo químico considera

\footnotetext{
${ }^{58}$ GERARQUE, Eduardo. Escolhas Energéticas. Boletim Fapesp.

http://www.agencia.fapesp.br/boletim_dentro.php?id=5523 acesso em 23/05/2006.

${ }^{59}$ Biodieselbr.com, Biodiesel Brasil.

http://www.biodieselbr.com/efeito-estufa/gases/emissoes.htm acesso em 23/04/2007.

${ }^{60}$ COPPE. Projeto Biodiesel.http://www.ivig.coppe.ufrj.br acesso em 02/01/2006.
}

que a ração terá um alto grau de toxicidade para os animais e humanos que a consuma. ${ }^{61}$

Estudos que computam a eficiência energética na produção de biocombustíveis nos alertam sobre os problemas de ineficácia desta opção. Estudos desenvolvidos por David Pimentel, professor de ecologia e agricultura da Universidade de Cornell demonstra que a produção de etanol e biodiesel consome mais energia do aquela proporcionada por estes combustíveis, não se constituindo em uma estratégia sustentável ${ }^{62}$.

Cientistas da universidade de Minnesota, EUA pesquisaram no período de dez anos, um conjunto de 16 plantas nativas, gramas e ervas para a produção energética e descobriram que elas produzem $238 \%$ maior quantidade de energia do que culturas como soja ou milho ${ }^{63}$.

As vantagens além de energéticas, também são ambientais pela manutenção da diversidade biológica e diminuição de gases do efeito estufa, geradores do aquecimento global. Quanto à geração destes gases, o Protocolo de Kioto de 1977, tenta estabelecer um acordo internacional fixando metas para a redução da emissão de gases tóxicos pelos países desenvolvidos. Este acordo estabeleceu também que, os países que não conseguissem cumpri-lo poderiam comprar créditos de carbono de outros países que possuam projetos de Mecanismo de Desenvolvimento Limpo. Os EUA, país campeão destas emissões, por enquanto ainda não assinou tal compromisso.

\section{Para a professora Mae-Wan - Ho, da universidade de Hong Kong:}

[...] os biocombustíveis têm sido propagandeados e considerados erroneamente como "neutros em carbono", como se não contribuíssem para o efeito estufa na atmosfera; quando são queimados, o dióxido de carbono que as plantas absorvem quando se

\footnotetext{
${ }^{61}$ COSTA NETO, Pedro R. et al . The utilization of used frying oil for the production of biodiesel. Quím. Nova., São Paulo, v. 23, n. 4, 2000. Disponível em: $<$ http://www.scielo.br/scielo.php?script=sci_arttext\&pid=S0100-

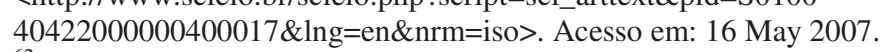

${ }^{62}$ LANG, Susan S. Cornell ecologist's study finds that producing ethanol and biodiesel from corn and other crops is not worth the energy.

${ }^{63}$ REBECCA. Latest development in renewable energy.

http://www.smm.org/buzz/blog/latest_development_in_renewable_energy acesso em 24/04/2007.
} 
desenvolvem nos campos é devolvido à atmosfera. Ignoram-se assim os custos das emissões de $\mathrm{CO} 2$ e de energia de fertilizantes e pesticidas utilizados nas colheitas, dos utensílios agrícolas, do processamento e refinação, do transporte e da infra-estrutura para distribuição ${ }^{64}$.

Poderia se acrescentar a estes custos o dispêndio de matéria e energia para o transporte destes biocombustíveis entre países e a redução das florestas para o cultivo das sementes selecionadas. Reduz-se a biodiversidade, a complexa relação ecossistêmica, o insubstituível patrimônio genético, em contrapartida estabelece-se o latifúndio, concentrador de riqueza e poder, explorador da mão-de-obra, beneficiado por renúncia fiscal e empréstimos subsidiados, monocultor e mecanizado, exportador de energia barata para os países energívoros e concentradores de riquezas.

Por fim, mas não em importância, sabemos da existência de apoio governamental à pesquisa que busca equacionar o Programa do biodiesel, em relação a isso, cabe-nos inquirir: porque renomados grupos de pesquisa e instituições ao serem contratados e/ou participarem de concorrências para receberem importantes auxílios financeiros para estudar o biodiesel, não realizam uma contextualização do assunto em termos: ecológico, histórico, social, político, econômico?

A redução da análise para atender a aspectos técnicos, específicos, aplicados em equipamentos, máquinas, seleção de sementes, ao não ser conjugada de forma mais ampla prejudicaria ou otimizaria o Programa do Biodiesel? Se ponderações críticas fossem feitas, haveria o risco de não se receber verbas? O papel do cientista é de tarefeiro especializado de grupo de pesquisa?

Os departamentos que atraem dinheiro são os mais prestigiados: os demais são negligenciados e até abandonados à sua própria sorte. $\mathrm{O}$ valor do docente pesquisador está diretamente relacionado com a quantidade de recursos financeiros que são atraídos para o grupo de pesquisa ao qual pertence. Não se questiona a natureza do projeto, quem interessa seus resultados, e como são aplicados os recursos que muitas vezes não se traduzem em efetiva melhoria da infra-estrutura

${ }^{64}$ PINTO, Edivan e outros. Op. Cit; http://www.brasildefato.com.br/v01/agencia/analise/omito-dos-biocombustiveis acesso em 26/03/2007. da instituição nem na qualidade do ensino de graduação ou mesmo pós-graduação ${ }^{65}$.

Consideramos assim, ser extremamente importante, questionar o objetivo imediato da produção de energia em larga escala por intermédio do óleo vegetal, para ser queimado nos motores, não se importando em que implicará todo este aparato produtivo e de consumo para a sociedade em seu patrimônio humano e ambiental.

\footnotetext{
65 MARTINS, Sérgio Roberto. A responsabilidade acadêmica na sustentabilidade do desenvolvimento: as ciências agrárias e a (falta de) percepção dos ecossistemas. www.agroeco.org/brasil/material/Eisforiasrmartins.rtf acesso em 11/09/2006.
} 